\title{
LETTER
}

\section{Letter to the Editor Regarding: Diabetic Peripheral Neuropathy as a Predictor of Asymptomatic Myocardial Ischemia in Type 2 Diabetes Mellitus: A Cross-Sectional Study}

\author{
Kalliopi Pafili · Nikolaos Papanas
}

Received: September 3, 2016 / Published online: September 26, 2016

(c) The Author(s) 2016. This article is published with open access at Springerlink.com

Diabetes mellitus (DM) frequently affects the nervous system [1]. This holds true both for the peripheral and for the autonomic nervous system [2]. Diabetic polyneuropathy (or distal symmetrical polyneuropathy [DPN] or, simply, peripheral neuropathy) is the most common manifestation of DM in the nervous system $[3,4]$. Of the autonomic nervous system, gastrointestinal autonomic neuropathy [5] and cardiovascular autonomic diabetic neuropathy (CAN) are those most widely studied. Importantly, CAN is a recognised harbinger of cardiovascular mortality [6-8].

What is known about the impact of diabetic polyneuropathy (DPN) on mortality? First, DPN is shown to be independently associated with mortality in a number of studies [9-11]. Second, neuropathic diabetic foot ulcers have also been associated with a 5-year mortality rate that approaches the amazing 50\% [12-14], exceeding the rate of several cancer types, including breast, prostate, colon, and Hodgin's

K. Pafili · N. Papanas $(\bowtie)$

Diabetes Centre, Second Department of Internal

Medicine, Democritus University of Thrace,

University Hospital of Alexandroupolis,

Alexandroupolis 68132, Greece

e-mail: papanasnikos@yahoo.gr disease [14]. In addition, Charcot osteoarthropathy may also be associated with increased mortality [15], more recently attributable to coronary artery disease [16-18].

In this issue of the journal, Baltzis et al. [19] have investigated the relationship between DPN and myocardial ischaemia (MI) in patients with type 2 diabetes mellitus (T2DM) and no history of cardiovascular events. Overall, 82 patients with DPN $(n=41)$ or without DPN $(n=41)$ were included. Among those with DPN, 15 had active ulcers. MI was estimated through Technetium-99 m Sestamibi Single-Photon Emission Computed Tomographic imaging expressed as Summed Stress Score (SSS): SSS $\geq 4$ was considered abnormal. Furthermore, two well-known indices of CAN (abnormal RR ratio and orthostatic hypotension) were used to detect this condition $[1,2,8]$. DPN was diagnosed clinically by the established examination system Neuropathy Disability Score (NDS) and defined as NDS $\geq 5[1,2]$. A negative $10-\mathrm{g}$ monofilament test served to exclude DPN [1, 2].

In this study [19], patients with DPN had a higher risk of abnormal SSS than those without DPN (46.3\% vs. $9.8 \%, p<0.001)$. Multivariate 
analysis identified NDS as the strongest predictor of SSS $(\beta=0.32, p=0.003)$, among other significant predictors, namely, waist circumference and gender. This association was not affected by the exclusion of patients with abnormal RR ratio or with ulcers $(\beta=0.32$, $p=0.003$, and $\beta=0.24, p=0.04$, respectively). This is important for two reasons. First, the RR ratio was also significantly associated with SSS in univariate $(\beta=-0.30, p=0.005)$ and multiple regression $(\beta=0.24, p=0.02)$ [19] and CAN has an established relationship with both cardiovascular mortality [6-8] and silent MI [20]. Secondly, MI was significantly higher in patients with DPN and foot ulcers $60 \%$ in patients with DPN and ulcer vs. $26.9 \%$ in those with DPN but without ulcer, $p<0.05$ ) [19]. In a recent meta-analysis, diabetic foot ulceration was also associated with an increased risk of fatal myocardial infarction [risk ratio (RR): 2.22, 95\% confidence interval (CI) 1.09, 4.53] [21]. It has also been identified as a significant predictor of silent MI in T2DM women [22]. Thus, it is suggested that the association between DPN and MI exceeds autonomic neuropathy and foot ulceration. Finally, in the present study [19], the area under the curve (AUC) of the receiver operator characteristics (ROC) curve $(0.76,95 \%$ CI $0.65-0.86$; $p<0.001)$ showed a fair to good performance of the NDS to discriminate patients with ischaemia.

The limitations of this interesting study may be summarised as follows. The first relates to the relatively limited number of patients with ulcers and the possibility of objective bias. Moreover, data on the timing of ulceration would be very useful to evaluate the relationship between active ulceration and abnormal SSS. A third limitation is inherent in the cross-sectional analysis which precludes the duration of follow-up. Moreover, average T2DM duration was 14.8 years, which may have influenced mortality as a confounding factor, given that the long T2DM duration is associated with a greater burden of silent MI [23]. However, this confounding effect is probably reduced by the virtue of excluding patients with a history of cardiovascular events. Finally, data on microalbuminuria and insulin usage would be highly welcome, because both these features $[23,24]$ are more prevalent among T2DM patients with vascular complications.

The clinical implication of the study by Baltzis et al. [19] is that DPN should not be underestimated as an index of asymptomatic MI in T2DM patients without known cardiovascular events. This is important irrespective of the exact causality. Indeed, the putative mechanism may relate to a common pathophysiological pathway, such as oxidative stress [25]. The authors have also proposed that NDS may prove useful to identify T2DM patients at risk of cardiovascular disease. Interestingly, there is evidence that asymptomatic high-risk T2DM patients, whose cardiovascular risk is controlled by an optimal medical treatment, should not be expected to improve hard outcomes (including cardiac death or non-fatal myocardial infarction) through the systematic detection of silent MI $[26,27]$. The COURAGE (Clinical Outcomes Utilising Revascularisation and Aggressive Drug Evaluation) [28] and BARI 2D (Bypass Angioplasty Revascularisation Investigation 2 Diabetes) [29] trials have demonstrated that the revascularisation of asymptomatic diabetic patients through the detection of silent MI may not provide an additive survival benefit with respect to the rates of death or major cardiovascular events, including myocardial infarction. Nonetheless, such lack of improvement contrasts with the favourable results in life expectancy (reduction in 5-year mortality from $58 \%$ to $36 \%$; relative reduction 
$38 \%$ for neuroischaemic and from 36\% reduction to $19 \%$; relative reduction $47 \%$ for neuropathic patients, all $p<0.001$ ) via aggressive cardiovascular risk management policy in a less selected population with diabetic foot ulcers [30]. Granted these conflicting results, NDS as a quick, relatively simple and widely used clinical tool of DPN $[31,32]$ may be taken to serve as a useful tool to evaluate the risk of cardiovascular complications of an early stage in T2DM. Indeed, NDS is cheaper and more practical than other costly techniques, such as stress-myocardial perfusion imaging, which cannot be widely implemented [33, 34]. However, both a cost-utility analysis (which was beyond the scope of the study by Baltzis et al. [19]) and larger randomised trials are vital to confirm its potential utility.

In conclusion, the new data point to a significant and clinically important association between DPN and myocardial infarction [19]. This study enriches the evidence on the association of DPN with coronary ischaemia, indicating that the former may serve as an indication of the latter. Given the association of MI with mortality [35], DPN may be taken to predict cardiovascular mortality as well. Accordingly, the efforts to improve early and reliable detection of DPN with new easy-to-use diagnostic tools [36-39] acquire an additional meaning in the context of improved screening for coronary ischaemia. In clinical practice, then, patients with DPN should receive even more zealous therapeutic attention.

Disclosures. N. P has been an advisory board member of Astra-Zeneca, Boehringer Ingelheim, MSD, Novo Nordisk, Pfizer, Takeda, and TrigoCare International; has participated in sponsored studies by Astra-Zeneca, Eli-Lilly, GSK,
MSD, Novo Nordisk, Novartis, and Sanofi-Aventis; has received honoraria as a speaker for Astra-Zeneca, Boehringer Ingelheim, Eli-Lilly, ELPEN, MSD, Mylan, Novo Nordisk, Pfizer, Sanofi-Aventis, and Vianex; and attended conferences sponsored by TrigoCare International, Eli-Lilly, Galenica, Novo Nordisk, Pfizer, and Sanofi-Aventis.

Open Access. This article is distributed under the terms of the Creative Commons Attribution-NonCommercial 4.0 International License (http://creativecommons.org/licenses/ by-nc/4.0/), which permits any noncommercial use, distribution, and reproduction in any medium, provided you give appropriate credit to the original author(s) and the source, provide a link to the Creative Commons license, and indicate if changes were made.

\section{REFERENCES}

1. Boulton AJ, Vinik AI, Arezzo JC, et al. Diabetic neuropathies: a statement by the American Diabetes Association. Diabetes Care. 2005;28:956-62.

2. Tesfaye S, Boulton AJ, Dyck PJ, et al. Diabetic neuropathies: update on definitions, diagnostic criteria, estimation of severity, and treatments. Diabetes Care. 2010;33:2285-93.

3. Papanas N, Ziegler D. Risk factors and comorbidities in diabetic neuropathy: an update 2015. Rev Diabet Stud. 2015;12:48-62.

4. Ziegler D, Papanas N, Vinik AI, Shaw JE. Epidemiology of polyneuropathy in diabetes and prediabetes. Handb Clin Neurol. 2014;126:3-22.

5. Gatopoulou A, Papanas N, Maltezos E. Diabetic gastrointestinal autonomic neuropathy: current status and new achievements for everyday clinical practice. Eur J Intern Med. 2012;23: 499-505.

6. Vinik AI, Maser RE, Ziegler D. Neuropathy: the crystal ball for cardiovascular disease? Diabetes Care. 2010;33:1688-90. 
7. Pop-Busui R, Evans GW, Gerstein HC, et al. Effects of cardiac autonomic dysfunction on mortality risk in the Action to Control Cardiovascular Risk in Diabetes (ACCORD) trial. Diabetes Care. 2010;33:1578-84.

8. Ziegler D, Zentai CP, Perz S, Rathmann W, Haastert B, Döring A. Prediction of mortality using measures of cardiac autonomic dysfunction in the diabetic and nondiabetic population: the MONICA/KORA Augsburg Cohort Study. Diabetes Care 2008;31:556-61.

9. Coppini DV, Bowtell PA, Weng C, et al. Showing neuropathy is related to increased mortality in diabetic patients-a survival analysis using an accelerated failure time model. J Clin Epidemiol. 2000;53:519-23.

10. Forsblom CM, Sane T, Groop PH, et al. Risk factors for mortality in Type II (non-insulin-dependent) diabetes: evidence of a role for neuropathy and a protective effect of HLA-DR4. Diabetologia. 1998;41:1253-62.

11. Soedamah-Muthu SS, Chaturvedi N, Witte DR, et al. Relationship between risk factors and mortality in type 1 diabetic patients in Europe: the EURODIAB Prospective Complications Study (PCS). Diabetes Care. 2008;31:1360-6.

12. Chammas NK, Hill RL, Foster AV, Edmonds ME. Is neuropathic ulceration the key to understanding increased mortality due to ischaemic heart disease in diabetic foot ulcer patients? A population approach using a proportionate model. J Int Med Res. 2002;30:553-9.

13. Moulik PK, Mtonga R, Gill GV. Amputation and mortality in new-onset diabetic foot ulcers stratified by etiology. Diabetes Care. 2003;26:491-4.

14. Robbins JM, Strauss G, Aron D, et al. Mortality rates and diabetic foot ulcers: is it time to communicate mortality risk to patients with diabetic foot ulceration? J Am Podiatr Med Assoc. 2008;98:489-93.

15. van Baal J, Hubbard R, Game F, Jeffcoate W. Mortality associated with acute Charcot foot and neuropathic foot ulceration. Diabetes Care. 2010;33:1086-9.

16. Papanas N, Pafili K, Maltezos E. Charcot osteoarthropathy and coronary artery disease in diabetes: the twilight of innocence? Acta Diabetol. 2016;53:123-4.

17. Bergis D, Bergis PM, Hermanns N, Zink K, Haak T. Coronary artery disease as an independent predictor of survival in patients with type 2 diabetes and Charcot neuro-osteoarthropathy. Acta Diabetol. 2014;51:1041-8.
18. Pitocco D, Marano R, Di Stasio E, et al. Atherosclerotic coronary plaque in subjects with diabetic neuropathy: the prognostic cardiovascular role of Charcot neuroarthropathy-a case-control study. Acta Diabetol. 2014;51:587-93.

19. Baltzis D, Roustit M, Grammatikopoulou MG, et al. Diabetic peripheral neuropathy as a predictor of asymptomatic myocardial ischemia in type 2 diabetes mellitus. Adv Ther (2016). Online first. doi:10.1007/s12325-016-0399-1.

20. Vinik AI, Ziegler D. Diabetic cardiovascular autonomic neuropathy. Circulation. 2007;115:387-97.

21. Brownrigg JR, Davey J, Holt PJ, et al. The association of ulceration of the foot with cardiovascular and all-cause mortality in patients with diabetes: a meta-analysis. Diabetologia. 2012;55:2906-12.

22. Diabetic foot ulcer is a significant predictor of silent myocardial ischemia in women with type 2 diabetes. Available at: http://www.omicsonline. org/diabetic-foot-ulcer-is-a-significant-predictor-ofsilent-myocardial-ischemia-in-women-with-type-2diabetes-2155-6156.1000161.php?aid=3332. Last accessed 07 Aug 2016.

23. Silent myocardial ischemia detection in asymptomatic diabetic patients. Available at: http://www.cu.edu.eg/data_journals/6/articles/1316/ submission/copyedit/1316-2555-1-CE.pdf. Last accessed: 11 Aug 2016.

24. Anand DV, Lim E, Hopkins D, et al. Risk stratification in uncomplicated type 2 diabetes: prospective evaluation of the combined use of coronary artery calcium imaging and selective myocardial perfusion scintigraphy. Eur Heart J. 2006;27:713-21.

25. Giacco F, Brownlee M. Oxidative stress and diabetic complications. Circ Res. 2010;107:1058-70.

26. Young LH, Wackers FJ, Chyun DA, et al. Cardiac outcomes after screening for asymptomatic coronary artery disease in patients with type 2 diabetes: the DIAD study: a randomized controlled trial. JAMA. 2009;301:1547-55.

27. Lièvre $M M$, Moulin $P$, Thivolet $C$, et al. Detection of silent myocardial ischemia in asymptomatic patients with diabetes: results of a randomized trial and meta-analysis assessing the effectiveness of systematic screening. Trials. $2011 ; 12: 23$.

28. Boden WE, O'Rourke RA, Teo KK, et al. Optimal medical therapy with or without PCI for stable coronary disease. $\mathrm{N}$ Engl J Med. 2007;356:1503-16. 
29. BARI 2D Study Group; Frye RL, August P, et al. A randomized trial of therapies for type 2 diabetes and coronary artery disease. $\mathrm{N}$ Engl J Med 2009;360:2503-15.

30. Young MJ, McCardle JE, Randall LE, et al. Improved survival of diabetic foot ulcer patients 1995-2008: possible impact of aggressive cardiovascular risk management. Diabetes Care. 2008;31:2143-7.

31. Abbott CA, Carrington $\mathrm{AL}$, Ashe $\mathrm{H}$, et al. The North-West Diabetes Foot Care Study: incidence of, and risk factors for, new diabetic foot ulceration in a community-based patient cohort. Diabet Med. 2002;19:377-84.

32. Weintrob N, Amitay I, Lilos P, et al. Bedside neuropathy disability score compared to quantitative sensory testing for measurement of diabetic neuropathy in children, adolescents, and young adults with type 1 diabetes. J Diabetes Complicat. 2007;21:13-9.

33. Cosson E, Paycha F, Paries J, et al. Detecting silent coronary stenoses and stratifying cardiac risk in patients with diabetes: ECG stress test or exercise myocardial scintigraphy? Diabet Med. 2004;21:342-8.
34. Avignon A, Sultan A, Piot C, et al. Osteoprotegerin is associated with silent coronary artery disease in high-risk but asymptomatic type 2 diabetic patients. Diabetes Care. 2005;28:2176-80.

35. Fox KA, Goodman SG, Klein W, et al. Management of acute coronary syndromes. Variations in practice and outcome; findings from the Global Registry of Acute Coronary Events (GRACE). Eur Heart J. 2002;23:1177-89.

36. Papanas N, Ziegler D. New vistas in the diagnosis of diabetic polyneuropathy. Endocrine. 2014;47:690-8.

37. Ziegler D, Papanas N, Zhivov A, et al. Early detection of nerve fiber loss by corneal confocal microscopy and skin biopsy in recently diagnosed type 2 diabetes. Diabetes. 2014;63:2454-63.

38. Papanas N, Ziegler D. Corneal confocal microscopy: a new technique for early detection of diabetic neuropathy. Curr Diab Rep. 2013;13:488-99.

39. Papanas N, Boulton AJ, Malik RA, et al. A simple new non-invasive sweat indicator test for the diagnosis of diabetic neuropathy. Diabet Med. 2013;30:525-34. 